Teknik not

\title{
Oklüzal Dental Apareylerin Üç Boyutlu Makyaj Uygulamalarında Kullanımı
}

\author{
The Use of Occlusal Dental Appliances in The Field of \\ Three Dimensional Makeup
}

\author{
Seçil Karakoca Nemli' (D), Merve Bankoğlu Güngör ${ }^{2}$ (D) , Yeşim Arsoy Baltacıoğlu ${ }^{3}(\mathbb{D}$
}

\section{ÖZET}

Sahne, film ya da televizyon endüstrisi ile diğer görsel tasarım alanlarında gerçekleştirilecek kurgularda karakter yaratmak amacıyla, kalıp alma, modelleme ve döküm yapma gibi tekniklerin kullanılmalarıyla jel köpük, silikon vb. dolgu malzemeleri elde edilen üç boyutlu parçaların yüz ya da vücuda yapıştııımaları ile oyuncunun dış görünüşünün değiştirilerek yeni bir görünüme büründürüldüğü çalışmaya üç boyutlu makyaj ya da özel efekt makyajı ad verilmektedir. Protetik makyaj görsel sanatlarda gelişmiş kozmetik etkiler yaratmayı amaçlayan ve protetik tekniklerin kullanımını kapsayan bir uygulamadır. Bu uygulama protetik ve dental apareylerin tasarımını, yapımını ve sanatçı üzerinde uygulanmasını içerir. Bir makyaj sanatçısı gerçekçi karakterler yaratabilmek için protetik makyajın her aşamasına özen göstermelidir. Çünkü diş apareyleri de protetik makyajın çok önemli bir aşamasını oluşturur. Bu makalenin amacı 2 farklı sahne karakterinin diş apareylerinin hazırlanması için görünür ışıkla polimerize rezinlerden yapılan oklüzal apareylerin dental teknikler ile yapımı ve bunların modifikasyonları ile istenen görünümün sağlanmasının anlatılmasıdır.

Anahtar Kelimeler: Oklüzal aparey; Üç boyutlu makyaj; Görünür ışıkla polymerize rezin

\begin{abstract}
For the purpose of creating a character on the fiction of which is made on the performance, movie or television and visual design fields, the work of changing the appearance of the actor/actress, by attaching of three-dimensional pieces, which are obtained by the using of backfill materials like gel-foam, silicon, etc., to the body or face of his/her, is called three dimensional or special effect makeup. Prosthetic makeup is a process of using prosthetic techniques to create advanced cosmetic effects for visual arts. The process includes designing, creating, and applying prosthetic and dental appliances. To create realistic characters, a makeup artist should pay attention on all stages of prosthetic makeup. An important aspect of creating realistic characters by prosthetic makeup is theatrical teeth appliances. The purpose of this article is to present dental techniques using occlusal appliances made of visible light polymerized resin and their modification to fabricate dental appliances for 2 screen characters.
\end{abstract}

Keywords: Occlusal appliance; Three dimensioanl makeup; Visible light polymerized resin

Makale gönderiliş tarihi: 16.08.2021 ; Yayına kabul tarihi: 11.09.2021

Iletişim: Dr. Seçil Karakoca Nemli

Gazi Üniversitesi Diş Hekimliği Fakültesi, Protetik Diş Tedavisi Anabilim Dalı, Ankara, Türkiye

E-posta: secilkarakoca@yahoo.com

${ }_{1}^{1}$ Prof. Dr., Gazi Üniversitesi Diş Hekimliği Fakültesi, Protetik Diş Tedavisi Anabilim Dalı, Ankara, Türkiye

${ }^{2}$ Doç. Dr., Gazi Üniversitesi Diş Hekimliği Fakültesi, Protetik Diş Tedavisi Anabilim Dalı, Ankara, Türkiye

${ }^{3}$ Dr. Öğr. Üyesi, Hacettepe Üniversitesi Devlet Konservatuarı, Ankara, Türkiye 


\section{GíRiş}

Sahne, sinema ya da televizyonda bir metnin sahnelenmesi noktasında metin bazen tarihten bilinen bir kişiliğin (Atatürk, Napolyon vb.), anatomik anormalliklerin (Fil Adam, Quasimodo vb.), doğaüstü varlıkların (peri, elf vb.), korku karakterlerinin (cadı, şeytan, vampir, zombi vb.) ya da oyuncunun yıllar sonraki halinin gösterileceği bir sahnede yaşlanmış görünümünün izleyiciye sunulmasını gerektirir. Anatomik olarak farklı tasarlanan bu karakterlerin görsellerinin sahneye taşınması noktasında oyuncunun tamamen farklı bir görünüme büründürülmesi, yüz ve vücuttaki uzuvların ilgili fantastik tasarım ile uyumlu olarak değiştirilmesi için üç boyutlu makyaj tekniklerinin kullanılması gerekir. Bu teknikler oyuncudan ölçü alınması, ölçüden çalışılacak olan uzvun kopyasının çıkarılması, bu kopya üzerinde tasarımla eşleşen modelajın yapılması, modellenen parçanın negatifinin çıkarılması ve negatife silikon esaslı materyalin uygulanması şeklinde işleyen bir süreçtir. Son olarak parçalar oyuncunun yüzüne yerleştirilerek sabitlenir ve üstüne tasarıma uygun biçimde renklendirme yapılarak makyaj tamamlanır. Tasarımın gerektirdiği ölçüde saçlı parçalar ve perukalar ile efekt lenslerin kullanımı da tamamlayıcı unsurlardır. Özellikle insani görünümden uzaklaşmış bir karakter çalışmasında her uzuv (göz, burun, ağız, kulaklar vb.) değiştirilirken, dişlerin insan dişi görünümünde kalması görsel bütünlüğü olumsuz etkileyecek oldukça önemli bir faktördür ve bu değişimin dikkate alınmadan yapıldığı bir çalışmanın profesyonel bir çalışma olması beklenemez. Yalnızca fantastik tiplemelerde değil aynı zamanda gerçekçi tasarlanan tip ya da karakterler için de tasarıma uygun diş apareyleri, görsel bütünlüğü sağlama ve inandırıcılık açısından yüksek öneme sahiptir. ${ }^{1,2}$

Protetik sahne makyajında kullanılan diş apareylerinin gerçekçi görünüme sahip olmasının yanı sıra karaktere özgü olması, yeterli stabiliteye sahip olması, kolay takılıp çıkarılabilmesi, kullanım esnasında oyuncuyu rahatsız etmemesi ve dokularla uyumlu olması gerekmektedir. Bu nedenle sahne makyajı uzmanları, diş apareylerinin yapımında diş hekimleri tarafından hazırlanan kaide plaklarının yapımını önermektedir. ${ }^{1}$ Protetik sahne makyajında karakterlere ait diş apareylerinin geleneksel yapım tekniği; oyuncudan geri dönüşümsüz hidrokolloid veya elastomerik ölçü maddesi ile ölçü alınması, alçı modellerin elde edilmesi, izole edilen modeller üzerine hamur kıvamındaki otopolimerize akrilik rezinin plaka haline getirilip adapte edilmesi, plağın sınırlarının düzenlenmesinden sonra ısı ve basınç altında polimerizasyonun yapılması, plağın ağızda kontrolü sonrasında karaktere özgü diş ve dişeti yapılarının ilave edilmesi ve apareyin gerekiyorsa dış boyamasının yapılması aşamalarını kapsamaktadır. ${ }^{1,2}$ Ancak bu yapım tekniği teknik hassasiyet gerektirmekte ve zaman almaktadır. ${ }^{3-5}$ Geliştirilmiş dental rezinler kullanılarak sahne makyajında kullanılan diş apareylerinin yapım tekniğinin geliştirilebileceği düşünülmüştür.

Oklüzal apareylerin diş hekimliğinde temporomandibular bozukluklar, bruksizm, oklüzal atrizyonlar, migren ve apne tedavilerinde kullanımı ve sportif ağız koruyucu gibi çeşitli kullanım alanları bulunmaktadır.6-9 Değişik amaçlarla kullanılan bu oklüzal apareylerin yapımında kullanılan materyaller ve yapım teknikleri de farklılık gösterebilmektedir. Ancak tüm oklüzal apareylerin dişlerle iyi bir adaptasyon gösterme, yeterli retansiyon ve tutuculuk sağlama ve dokularda mekanik veya kimyasal irritasyon oluşturmama gibi temel gereksinimleri karşılaması gerekmektedir. $^{3,6}$ Protetik sahne makyajında kullanılan diş apareylerinin yapımında da dental oklüzal apareylerin yapım prensipleri ve gelişmiş rezin materyallerinin kullanımının yararlı olacağı düşünülmektedir. Böylece canlandırılan karakterlerin diş apareylerini uzun süreler boyunca ve tekrarlayan sahnelerde kullanımları mümkün olabilir, sahneler arasında modifikasyon mümkün olur ve sahnede kullanım esanasında sanatçı rahat hareket edebilir.

Bu teknik raporda, protetik sahne makyajı ile oluşturulan 2 farklı karakterin dental oklüzal apareylerinin ışıkla polimerize rezin materyali kullanılarak yapımı anlatılmaktadır.

\section{DENTAL TEKNIK}

\section{Teknik 1}

Geri dönüşümsüz hidrokolloid ölçü maddesi (Jeltrate; Dentsply Caulk, Milford, DE) ile maksiller ve mandibular arkların ölçüsü alındı. ADA Tip III alçı (Quickstone; Whip Mix Corp, Louisville, KY) ile çaIışma modeli elde edildi ve 1 saatlik sertleşme süresi beklendi. Modeldeki undercut alanları kaide mumu (Base Plate Wax; Kerr Dental Laboratory Products, 


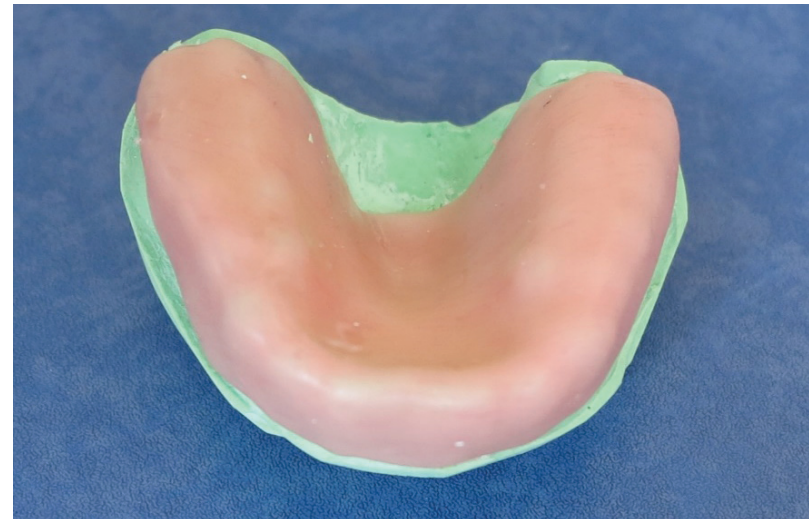

Resim 1. Görünür ışıkla polimerize rezinin model üzerine adapte edilmesi

West Collins Orange, CA) ile bloke edildi ve ince bir tabaka alçı izolasyon materyali (Isolant/C.M.S; Dentsply Detrey $\mathrm{GmbH}$, Dreieich, Almanya) uygulandı.

Plaka şeklindeki görünür ışık ile polimerize rezin materyali (visible light polymerized (VLC) Triad Denture Base Material; Dentsply International Inc., York, PA) dişler ve gingival bölgenin görünür kısmını kaplayacak şekilde model üzerine adapte edildi. Işık ile polimerize rezin plakanın fazlalıkları bir bistüri ile kesildi ve model ışık polimerizasyon cihazına (Triad 2000; Dentsply International, Inc.) yerleştirilerek $4 \mathrm{dk}$ ön polimerizasyonu yapıldı. Sertleşmiş olan rezin aparey modelden ayrıldı. Üretici firmanın tavsiyelerine uygun olarak apareyin tüm yüzeyleri oksijen bariyeri (TRIAD Air Barrier Coating; Dentsply International Inc.) materyali ile kaplandı ve ışık polimerizasyon cihazında 6 dakika boyunca bekletilerek polimerizasyonu tamamlandı (Resim 1).

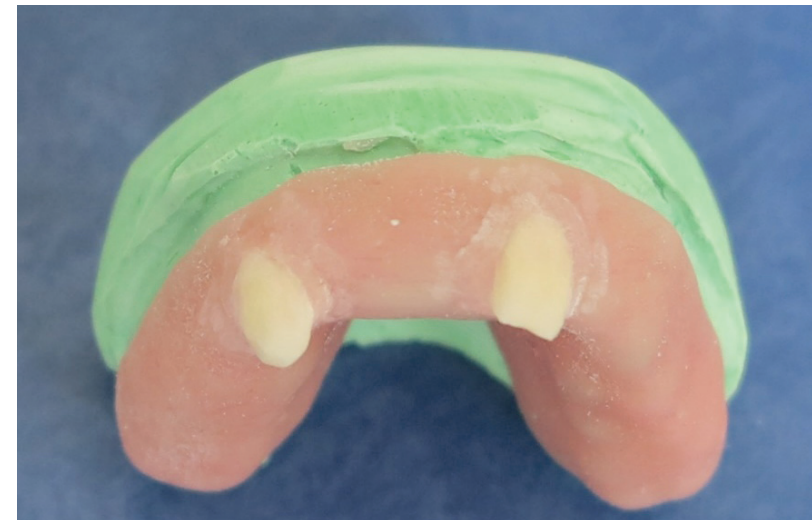

Resim 2. Akrilik rezin protez dişlerin modifikasyonu

Rezin aparey yumuşak bir fırça ile ılık su altında temizlendi. Apareyin kenarlarındaki materyal fazlalıkları karbid frez (Laboratory Carbide Bur; GC Corp, Tokyo, Japonya) ile aşındırılarak uzaklaştıııldı ve keskin kenar ve köşelerin kalmaması için kontrol edildi. Apareyin ağız içindeki uyumu kontrol edildi. Apareyin görünür yüzeylerinde dişsiz ağız mukozası görünümünü taklit edecek yüzey yapısı oluşturuldu.

13, 21 ve 42 numaralı akrilik rezin dişlerin (Major Plus; Major Dental, Moncalieri, Italya) lingual kısımları karbit frez ile aşındıılarak inceltildi ve bu yüzeylere bağlayıcı ajan (Triad VLC Bonding Agent; Dentsply International Inc.) uygulandı. Protez dişleri aparey üzerinde uygun yerlerine küçük bir parça ışık ile polimerize rezin parçası ile sabitlendi ve LED ışığ (DB686Mocha,LK-G25; Coxo, Gua, Çin) ile polimerize edildi. Karbid frez ile dişlerin etrafındaki fazla rezin materyali aşındırılarak alındı ve yüzeyde küçük modifikasyonlar yapıldı (Resim 2).

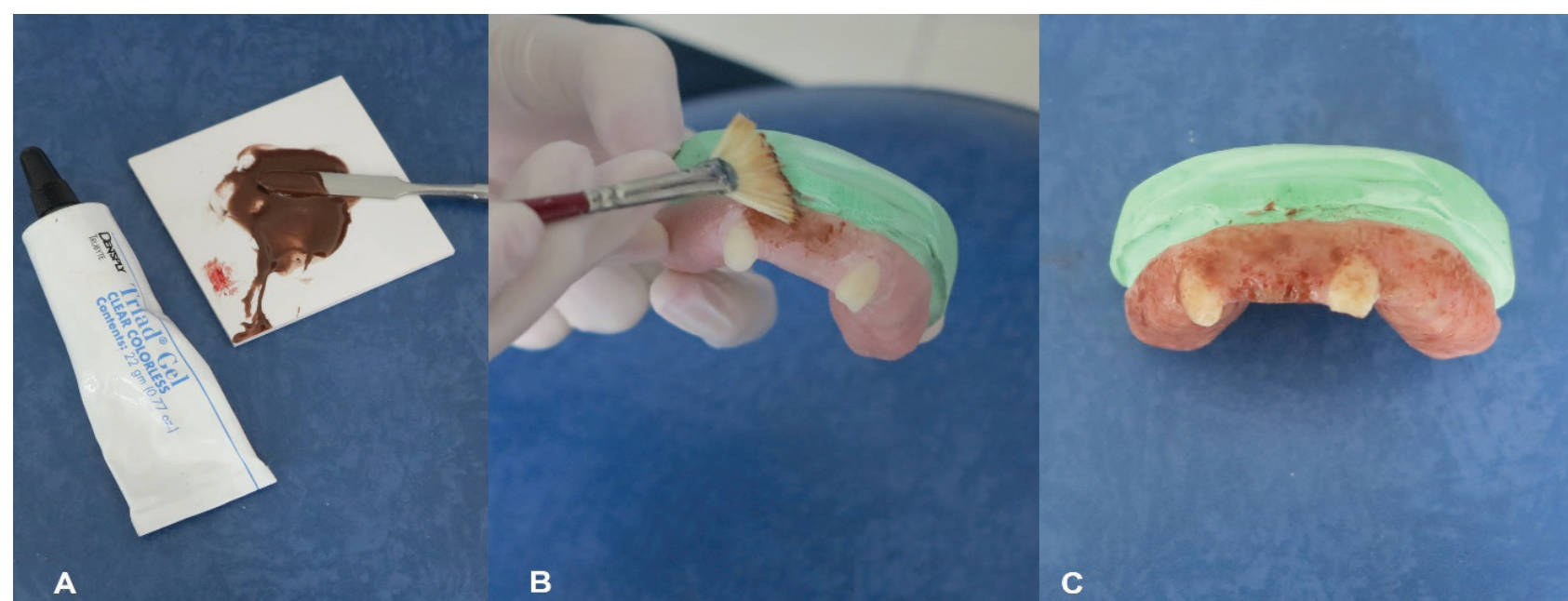

Resim 3. A. Kahverengi iç boyama renklendirme ajanı ilave edilmesi B. Renklendirmenin dış yüzeye uygulanması C. Sağlıksız mukoza görünümü 


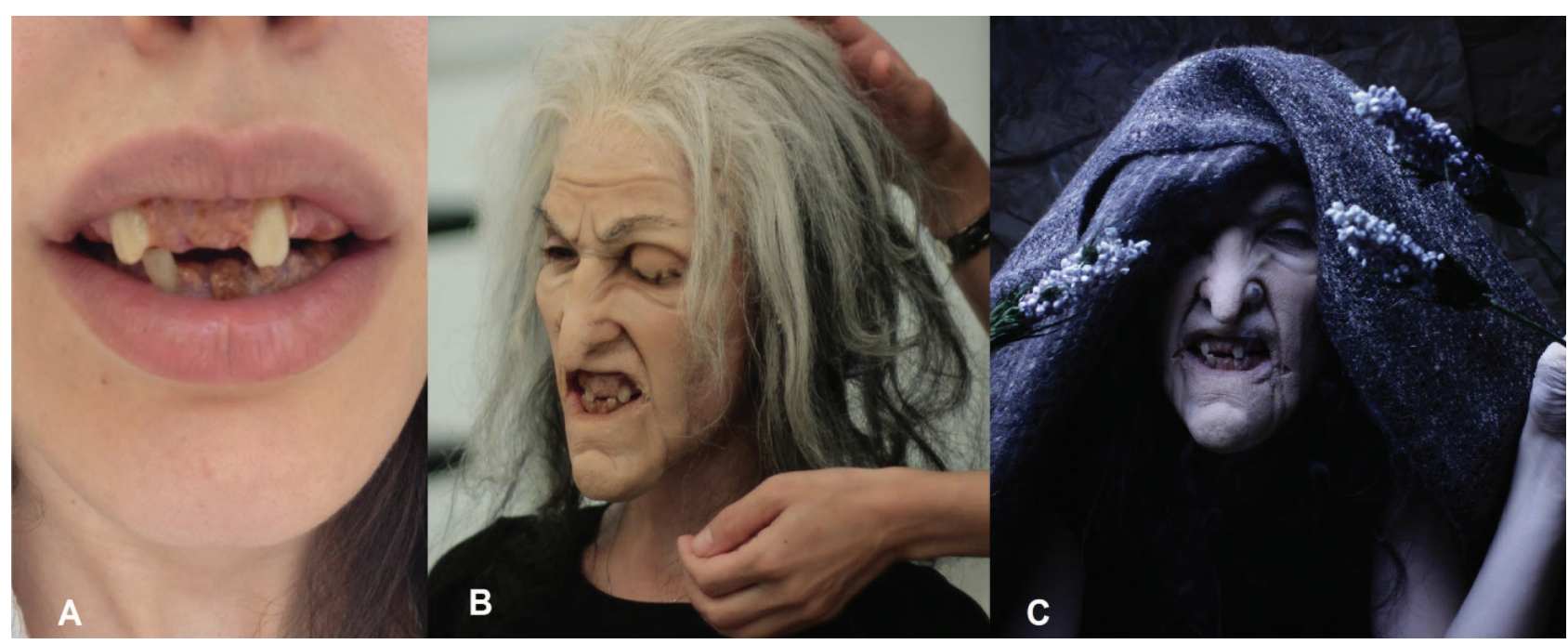

Resim 4. A. Apareyin ağız içi kontrolü B. Protetik makyaj C. Apareyin üç boyutlu makyaj ile beraber uygulanması

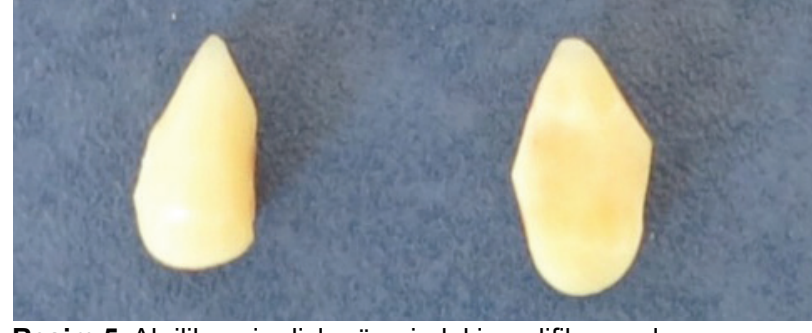

Resim 5. Akrilik rezin dişler üzerindeki modifikasyonlar

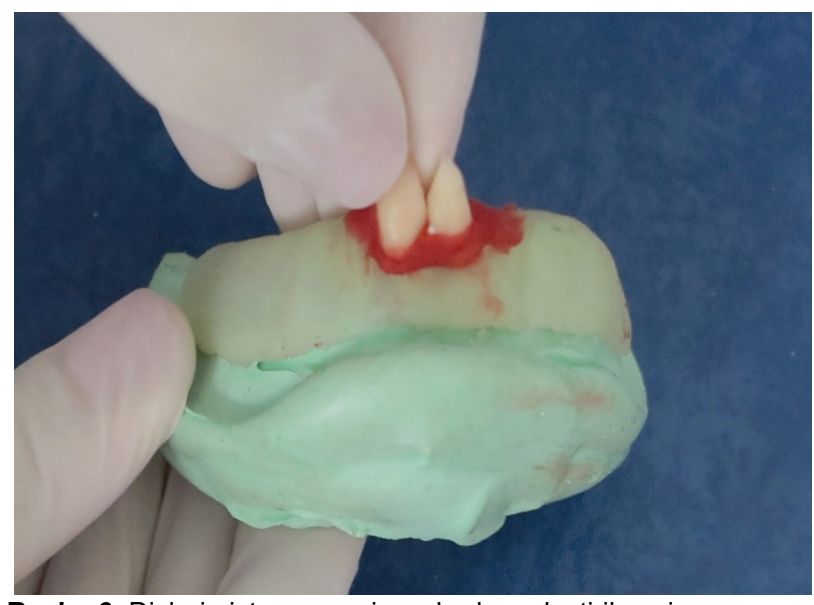

Resim 6. Dişlerin istenen pozisyonlarda yerleştirilmesi

Jel kıvamındaki şeffaf ışıkla polimerize rezin materyali (Triad Gel; Dentsply International Inc.) içine bir miktar kahverengi boya (Dry Pigment; Cosmesil; Principality Medical Ltd, South Wales, Birleşik Krallık) ilave edilerek karıştırıldı. Maksillofasiyal silikonların renklendirilmesinde kullanılan toz halindeki boya maddesi dokularla uyumlu ve polimer esaslı materyaller içinde çözünebilen yapıda olması sebebiyle bu amaçla kullanıma uygundur. Jel kıvamındaki rezin ve boya homojen bir şekilde karıştırıldıktan sonra bir fırça yardımıyla apareyin görünen yüzeylerine sürülerek koyulaşmış mukoza görümü sağlandı (Resim 3). Jel kıvamındaki ışıkla polimerize rezin led ışığı uygulayarak polimerize edildi. Üretici talimatları göz önüne alınarak her 3 mm'lik rezin yüzeyi 10 saniye ışığa maruz bırakıldı. Aparey modelden ayrılarak üretici önerilerine uygun olarak tüm yüzeylerine tekrar oksijen bloke edici (Triad Air Barrier Coating; Dentsply International Inc.) uygulandı ve polimerizasyon cihazında 2 dakika polimerize edildi. Aparey protetik sahne makyajı uygulaması ile canlandırılan bir karakterde kullanıldı (Resim 4).

\section{Teknik 2}

Çalışma modeli Teknik 1'de anlatılan şekilde hazırlandı. Transparan ışık ile polimerize rezin plaka (Triad Transsheet Material; Dentsply International Inc.) çalışma modeli üzerine adapte edildi. Akrilik rezin dişler, canlandırılan sahne karakterinin dişlerine uygun şekilde modifiye edildi ve bu dişlerin kaide ile bağlantı kuracak yüzeylerine ince bir tabaka bağlayıcı ajan (Triad VLC Bonding Agent; Dentsply International Inc.) uygulandı (Resim 5). Bir parça ışık ile polimerize rezin içine kırmızı iç boyama materyali (Dry Pigment; Cosmesil; Principality Medical Ltd.) ilave edilerek elde homojen bir karışım elde edilene kadar karıştırıldı. Bu renklendirilmiş rezin materyali, modifiye edilmiş protez dişlerinin kaide üzerine yerleştirilmesinde kullanıldı. Dişler istenen pozisyonda yerleştildikten sonra LED ışığı polimerizasyon kaynağı (DB686Mocha, LK-G25; Coxo, Gua, Çin) ile polimerize edildi (Resim 6). 
Dişlerin yerleştirilmesi tamamlandıktan sonra kalan kırmızı renklendirilmiş rezin şeffaf apareyin dış yüzüne ince bir tabaka halinde yayılıp polimerize edildi. Jel kıvamındaki ışık ile polimerize rezin içine siyah iç boyama materyali (Dry Pigment; Cosmesil; Principality Medical Ltd.) ilave edilerek homojen bir karışım elde edilene kadar karıştırıldı ve apareyin dış yüzüne fırça ile sürüldü (Resim 7). Teknik 1'de anlatılan işlemler yapılarak aparey tamamlandı (Resim 8).

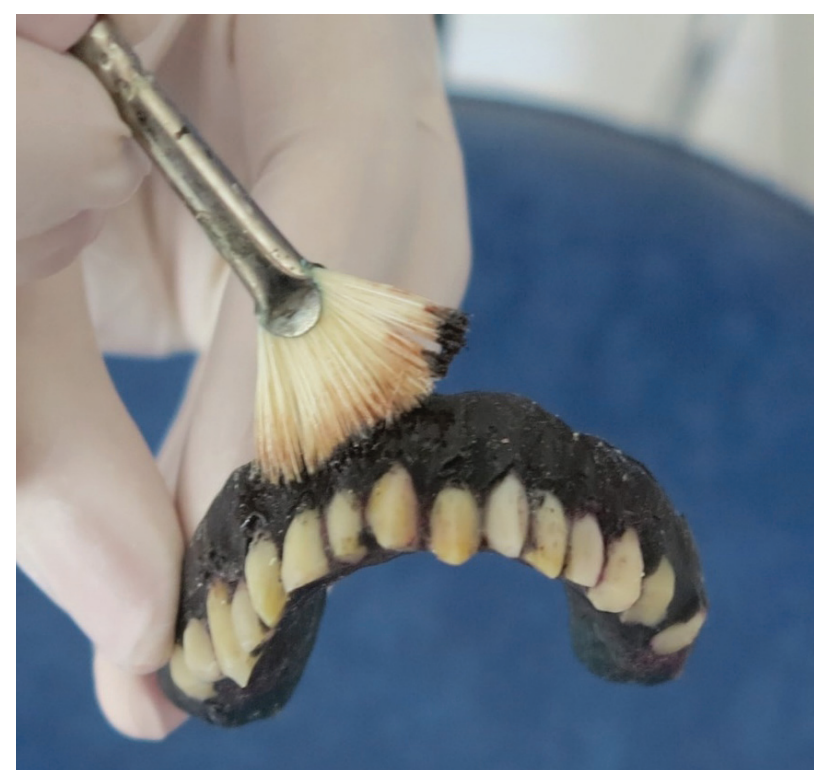

Resim 7. Siyah iç boyama renklendirme ajanının ilave edilmesi

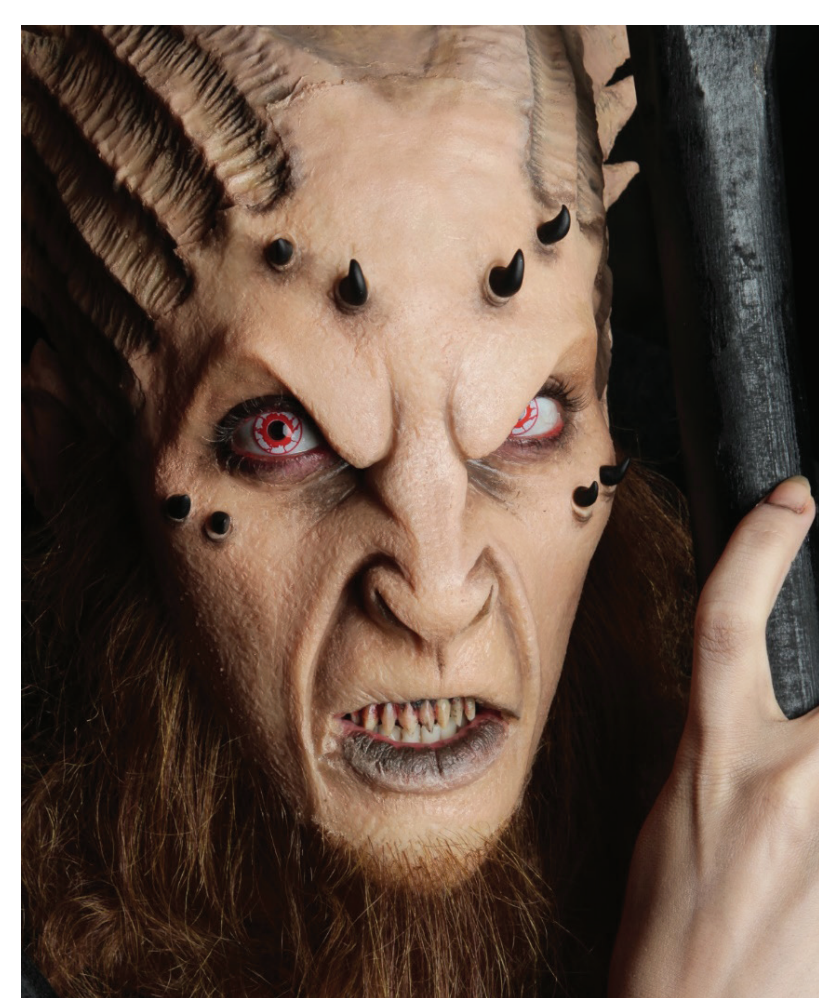

Resim 8. Apareyin 3 boyutlu makyaj ile beraber uygulanması

\section{TARTIŞMA}

Bu teknik raporda diş hekimliğinde geleneksel kimyasal polimerize ve ısı ile polimerize rezinler yerine kullanılan modern materyaller olan ışık ile polimerize rezinlerin 3 boyutlu sahne makyajı ile canlandırılan karakterlerin diş apareylerinin yapımında kullanımı anlatılmaktadır. Işık ile polimerize rezinler dental ve medikal alanda; kullanım kolaylığı, boyutsal stabilite ve düşük toksisite gibi önemli avantajları sayesinde tercih edilmektedirler. ${ }^{5} \mathrm{Bu}$ teknikte polimerize olmamış materyalin uzun bir çalışma süresine sahip olması ve uygulama tamamlandığında ışık uygulaması ile hızlı bir şekilde polimerizasyonun sağlanması materyalin önemli özellikleridir. ${ }^{3}$ Çünkü sanatsal bir çalışma istenen görünüm ve etkinin sağlanabilmes için uzun zaman gerektirebilmektedir. Işık ile polimerize rezinler dental laboratuvar ve kliniklerde çok geniş kullanım alanına sahip olmalarının yanı sıra bu raporda anlatılan örneklere benzer şekilde sahne karakterlerinin üç boyutlu makyajında diş apareylerinin yapımı gibi yeni bir kullanım alanına sahip olabilirler.

Işık ile polimerize rezinlerin diğer bir avantajı da hem laboratuvar aşamalarını yapan kişi hem de kullanıcı için sağlık üzerine olan etkileridir. Kimyasal olarak polimerize olan rezinler bir monomer ve polimerin karıştırılması ile başlayan kimyasal reaksiyon sonucu polimerizasyonun gerçekleşmesi esasına dayanır ve kimyasal reaksiyon esnasında ortaya çıkan zararlı buharlar kullanıcı tarafından solunabilir. ${ }^{3} \mathrm{Bu}-$ nun monomer buharının solunmasının toksik etkileri çalışmalarla ortaya koyulmuştur., ${ }^{3,4}$ Polimerizasyon öncesi hamur kıvamında olup, ışık geçirmeyen kutularda saklanan ışık ile polimerize rezinler, şekillendirilip görünür ışık uygulaması ile polimerize edilmekte böylece insan sağlığına zararlı bir etki yaratmamaktadırlar. Ayrıca artık monomer adı verilen, rezin kitlesi içinde polimerize olmamış monomerin tükürüğe geçerek yumuşak dokular için bir irritasyon kaynağı olarak davrandığı bilinmektedir. ${ }^{10-12}$ Polimerizasyon sonrası rezin kitlesinde artık monomer kimyasal polimerizasyonda diğer polimerizasyon yöntemlerine göre daha yüksek bulunmuştur. ${ }^{13}$ Üç boyutlu sahne makyajının önemli bir parçası olan diş apareyleri, dental protezlere göre çok daha kısa kullanım süresine sahip olması sebebiyle genellikle kimyasal polimerize akrilik rezinden hazırlanmaktadır. Ancak sahnede uzun sürebilen kullanımla beraber artık monomer salınımı ve buna bağlı irritasyon, alerjik re- 
aksiyon ve doku hassasiyeti risklerini ortadan kaldırmak için doku uyumu daha iyi olan ışık ile polimerize rezin kullanımı tavsiye edilebilir. ${ }^{3}$

Işık ile polimerize rezin materyallerinin iç boyama ile renklendirilmesi sahne makyajında kullanılan diş apareylerine gerçekçi bir görünüm kazandırdı ve bu etki kullanım süresi boyunca stabil oldu. Ancak ışık ile polimerize rezin içine maksillofasiyal protez silikonları için üretilmiş pigmentlerin ilave edilmesi materyalin mekanik özellikleri üzerinde olumsuz etkiler meydana getirme riski göz önünde bulundurulmalıdır. Bu apareylerin kısa kullanım süreleri ve çiğneme kuvvetlerine maruz kalmamaları bu olası olumsuz etkinin göz ardı edilebilmesini sağlar. Bu raporda kullanılan ışık ile polimerize rezin materyalinin dezavantaj olarak değerlendirilebilecek özelliği ise standart kimyasal polimerize akrilik rezinlere göre daha pahalı olmasıdır. ${ }^{3}$ Ayrıca sisteme ait ışık polimerizasyon ünitesi gerekmektedir ve bu da ilave bir maliyet getirir. Ancak toz-likit formunda olan rezin sistemlerinde monomer buharının ve ince polimer tozlarının laboratuvar ortamında çalışanlara zarar vermemesi için iyi bir havalandırma sistemi kurulmaSı, polimerizasyon cihazından daha maliyetli olduğu da göz önünde bulundurulmalıdır. ${ }^{3}$

\section{SONUÇ}

Üç boyutlu sahne makyajı için diş apareylerinin yapımında sanatçı ve diş hekiminin birlikte çalışması eserin başarısını artıırmıştır. Apareyin ağza olan uyumu, stabilitesi ve kolay takıp çıkarılabilmesi diş hekimi tarafından sağlanmış, karakterizasyonu makyaj sanatçısı ve diş hekiminin birlikte çalışması ile tamamlanmıştır. Bu uygulamada kimyasal polimerize akrilik rezin yerine ışık ile polimerize rezin kullanımı; manipülasyon kolaylığı, uzun çalışma süresi ve çalışma süresi sonunda hızlı polimerizasyon gibi avantajlar sağlamıştır. Ayrıca ışık ile polimerize akrilik rezin hem apareyi yapanlar hem de kullanan sanatçı için sağlık ile ilgili riskleri en aza indirmektedir.

\section{KAYNAKÇA}

1. Debreceni T. Special makeup effects for stage and screenMaking and applying prosthetics.UK:Focal Press; 2009.

2. Sartor D, Pivovarnick J. Theatrical FX Makeup. History Ink Books; 2001.

3. Alves PV, Bolognese AM, Polley JW, Figueroa AA. Use of visible light-curing acrylic resins to manufacture occlusal splints: health considerations for clinicians and laboratory personnel. $J$ Oral Maxillofac Surg 2008;66:2638-41.

4. Lee DH, Lim BS, Lee YK, Ahn SJ, Yang HC. Involvement of oxidative stress in mutagenicity and apoptosis caused by dental resin monomers in cell cultures. Dent Mater 2006;22:1086-92.

5. Lewis EA, Ogle RE, Sorensen SE, Zysik DA. Clinical and laboratory evaluation of visible light-cured denture base resins and their application to orthodontics. Am J Orthod Dentofacial Orthop 1988;94:207-15.

6. Okeson JP. Management of temporomandibular disorders and occlusion. $7^{\text {th }}$ Edition, Elsevier; 2012.

7. Barnes MF, Geary JL, Clifford TJ, Lamey PJ. Fitting acrylic occlusal splints and an experimental laminated appliance used in migraine prevention therapy. Br Dent J 2006;200:283-6.

8. Antonelli J, Hottel TL, Siegel SC, Brandt R, Silva G. The occlusal guard: a simplified technique for fabrication and equilibration. Gen Dent 2013;61:49-54.

9. Gagnon $Y$, Mayer P, Morisson F, Rompré PH, Lavigne GJ. Aggravation of respiratory disturbances by the use of an occlusal splint in apneic patients: a pilot study. Int J Prosthodont 2004; 17:447-53.

10. Mc Cabe JF, Basker RM. Tissue sensitivity to acrylic resin. Br Dent J 1976;140:347-50.

11. Miettinen VM, Vallittu PK. Release of residual methy methacrylate into water from glass fibre-poly (methyl methacrylate) composite used in denture. Biomaterials 1997;18:181-5.

12. Vallittu PK, Ruyter IE, Buykuilmaz S. Effect of polymerization temperature and time on residual monomer content of denture base polymers. Eur J Oral Sci 1998;106:588-93.

13. Huggett R, Brooks SC, Bates JF: The effect of different curing cycles on the dimensional accuracy of acrylic resin denture base materials. Quint Dent Tech 1984;8:81-5. 